\title{
Net dissolved inorganic nitrogen production in hyporheic mesocosms with contrasting sediment size distributions
}

\author{
Brett N. Harvey • Michael L. Johnson • \\ Joseph D. Kiernan • Peter G. Green
}

Received: 22 February 2010/Revised: 15 September 2010/Accepted: 24 September 2010/Published online: 7 October 2010

(C) The Author(s) 2010. This article is published with open access at Springerlink.com

\begin{abstract}
The interstitial spaces within streambeds are recognized as an important location of dissolved inorganic nitrogen (DIN) transformations in streams. However, it remains uncertain how physical characteristics of streambeds affect the magnitude and net outcome of subsurface nitrogen transformations. We tested whether the size distribution of streambed sediments, in isolation from the influence of streambed topography and groundwater upwelling, could affect net DIN uptake or production along interstitial flow paths. Mesocosms constructed from PVC pipe (15 cm diameter $\times 1 \mathrm{~m}$ long) were filled with either coarse gravel/cobble or gravel/cobble mixed with finer sediments (5 mesocosms per sediment treatment). Mesocosms were submerged in a stream and
\end{abstract}

Handling editor: Luigi Naselli-Flores

B. N. Harvey $(\bowtie) \cdot$ M. L. Johnson · J. D. Kiernan

Center for Watershed Sciences, University of California, One Shields Avenue, Davis, CA 95616, USA

e-mail: bnharvey@ucdavis.edu

M. L. Johnson

e-mail: mbjohnson@ucdavis.edu

J. D. Kiernan

e-mail: jdkiernan@ucdavis.edu

P. G. Green

Department of Civil and Environmental Engineering, University of California, Davis, CA 95616, USA

e-mail: pggreen@ucdavis.edu oriented, so that surface water flowed through the sediments. After 2 months incubation, we measured DIN in interstitial water at $20 \mathrm{~cm}$ intervals and dissolved oxygen at $10 \mathrm{~cm}$ intervals along mesocosm flow paths. In both sediment types, DIN concentrations increased longitudinally along mesocosm flow paths in the direction of interstitial flow, indicating net DIN production. Although DIN increased to higher concentrations in mesocosms with fine sediments, greater exchange flow through coarse sediments resulted in similar rates of net DIN production and delivery to surface water. Production of DIN in both sediment types was concentrated within the first $10 \mathrm{~cm}$ of interstitial flow paths, with no significant production further along the flow paths. Coarse sediments had higher rates of oxygen consumption per unit sediment volume than the coarse-fine sediment mix, suggesting interstitial water velocity may be an important factor affecting hyporheic microbial metabolism.

Keywords Hyporheic exchange flow - Stream · Sediment size $\cdot$ Respiration $\cdot$ Nitrate production

\section{Introduction}

The availability of dissolved inorganic nitrogen (DIN $=\mathrm{NH}_{4}{ }^{+}+\mathrm{NO}_{3}{ }^{-}+\mathrm{NO}_{2}{ }^{-}$) commonly limits autotrophic and heterotrophic productivity in many aquatic environments, including small streams 
(Dodds, 2007; Dodds \& Cole, 2007). Therefore, factors affecting the movement, retention, and transformations of nitrogen in small streams can have important consequences for local trophic status and the trophic status of larger downstream water bodies (rivers, lakes, and estuaries) (Alexander et al., 2000; Peterson et al., 2001). While the photic zone on and above the streambed surface is an important site of DIN uptake and assimilation by plants and algae, a major site of DIN regeneration, denitrification, and other nitrogen transformations is the saturated interstitial spaces beneath the streambed surface, where bacterial biofilms metabolize organic matter (Brunke \& Gonser, 1997; Boulton et al., 1998). Although research has shown the relative magnitude and net outcome of subsurface, nitrogen transformations are largely dependent on the availability of oxygen (Findlay, 1995; Sheibley et al., 2003) and labile organic matter along subsurface flow paths (Baker et al., 1999; Butturini et al., 2000; Arango et al., 2007), relatively little is known about the influence of streambed physical characteristics on these transformations. For this reason, we employed in situ flowthrough mesocosms to determine if net DIN uptake or production occurring along interstitial flow paths differed between two sediment mixes with different grain size distributions.

In small streams, a substantial portion of surface flow can pass transiently along shallow subsurface flow paths (Harvey \& Bencala, 1993; Kasahara \& Wondzell, 2003). Surface-subsurface exchange flow carries dissolved organic matter (DOM) and particulate organic matter (POM) into the streambed, where bacteria consuming organic matter convert excess organic nitrogen into $\mathrm{NH}_{4}{ }^{+}$. Under aerobic conditions, $\mathrm{NH}_{4}^{+}$is rapidly oxidized to $\mathrm{NO}_{3}{ }^{-}$ by chemoautotrophic nitrifying bacteria. Surfacesubsurface exchange flow returns regenerated $\mathrm{NH}_{4}{ }^{+}$ and $\mathrm{NO}_{3}{ }^{-}$to the photic zone where they are the important sources of DIN for algae and plants (Stanford \& Ward, 1988; Valett et al., 1994). Alternatively, oxygen consumption along slow moving flow paths creates anoxic conditions in which denitrifying bacteria metabolizing organic carbon transform DIN into $\mathrm{N}_{2}$ (Baker et al., 1999; Lefebvre et al., 2005), considered a sink for nitrogen in stream ecosystems because $\mathrm{N}_{2}$ cannot be assimilated by most primary producers (Duff \& Triska, 2000). Oxygen and organic matter availability (Valett et al., 1996;
Lefebvre et al., 2005) and interstitial microbial activity (Battin, 2000) are strongly influenced by streambed hydraulic conductivity, the ability of a porous media to transmit water. Since hydraulic conductivity is primarily a function of the size distribution of sediments, it stands to reason that the size distribution of sediments along subsurface flow paths should influence the relative magnitude of nitrogen transformations that occur in the streambed and ultimately the net uptake or output of DIN to surface water (Malard et al., 2002).

Although few studies have investigated the influence of sediment size distributions on interstitial nitrogen transformations under controlled conditions, a number of studies have compared hydrological properties, nutrient uptake characteristics or biochemical activities between streambed sediments derived from different parent lithologies, typically coarse granitic sediments versus finer sediments derived from volcanic tuff, schist or sandstonesiltstone (Valett et al., 1996; Morrice et al., 1997; Garcia-Ruiz et al., 1998; Grimaldi \& Chaplot, 2000; Minshall et al., 2000; Fellows et al., 2001; Lefebvre et al., 2005). Taken together, these studies demonstrate that streambeds with larger mean particle size and/or a smaller fraction of fine sediments have higher hydraulic conductivity, higher surface-subsurface exchange flow, larger subsurface exchange zone volume, and shorter average residence times along subsurface flow paths. Relative to streambeds composed of finer sediments, coarse sediment streambeds are also characterized by higher concentrations of interstitial oxygen and $\mathrm{NO}_{3}{ }^{-}$, lower concentrations of $\mathrm{NH}_{4}{ }^{+}$and higher infiltration rates of POM and solutes (i.e., DOM, DIN, $\mathrm{O}_{2}$ ) where surface water enters subsurface flow paths.

In contrast to the relatively consistent differences in hydrologic characteristics and solute gradients found between coarse and fine sediment streambeds, studies comparing metabolic activity, denitrification, and net $\mathrm{NO}_{3}{ }^{-}$gain or loss rates between streambed sediments of different grain size have found less consistent and sometimes conflicting results. Since these studies did not use a common metric to characterize grain size distribution, it is difficult to assess whether the inconsistencies between studies reflect differences in the range of compared grain sizes (i.e., coarse grain sizes in one study may represent fine grain sizes in another study). However, 
studies that shared a common metric generally examined a similar range (e.g., under $0.05 \mathrm{~mm}$ to 1-3 mm average grain size: Dodds et al., 1996; Claret \& Fontvieille, 1997; under $5 \times 10^{-4} \mathrm{~cm} \mathrm{~s}^{-1}$ to over $40 \times 10^{-4} \mathrm{~cm} \mathrm{~s}^{-1}$ hydraulic conductivity: Valett et al., 1996; Fellows et al., 2001; Lefebvre et al., 2005). The inconsistent responses of biochemical process rates to grain size distribution may also reflect more fundamental differences in experimental approach between studies. For example, studies that used sediment slurries in incubation vessels to measure microbial metabolic activity by fluorescein diacetate hydrolysis (e.g., Claret \& Fontvieille, 1997; Lefebvre et al., 2005), or denitrification rate by the acetylene block method (e.g., Dodds et al., 1996; Garcia-Ruiz et al., 1998; Lefebvre et al., 2005), usually found higher process rates associated with finer sediments, although Dodds et al. (1996) found that microbial activity measured by thymidine incorporation was greater in coarser sediments. In contrast, Valett et al. (1996) measured net $\mathrm{NO}_{3}{ }^{-}$loss along subsurface exchange flow paths in natural streambeds and found correlations with subsurface residence time and oxygen depletion, but reported no clear distinction in $\mathrm{NO}_{3}{ }^{-}$ loss rates between streambeds of different sediment size. Working in the same streams as Valett et al. (1996), Fellows et al. (2001) measured hyporheic metabolism per sediment volume using hyporheic microcosms with recirculating water and measured hyporheic areal metabolism using a whole-stream diel respiration approach. Even though per volume respiration rates were nearly indistinguishable between microcosms incubated in the different streams, measurements of areal hyporheic respiration in the coarser sediment streambed were three and seven times higher than the largest areal respiration rate in the finer sediment stream, demonstrating the importance of exchange zone size to hyporheic metabolism under natural hydrological conditions. In an earlier study, Jones (1995) also used recirculating flow-through microcosms to examine the influence of sediment size on hyporheic respiration rates and found respiration rates per sediment volume declined with increasing sediment size.

These studies suggest that microbial process rates measured in sediment slurry incubations elevate the importance of sediment surface area because reactant exposure to sediment surfaces is not constrained by the hydrological differences between natural streambeds. The mesocosm studies cited above also did not account for differences in exchange zone volume between streambeds. On the other hand, studies that sampled interstitial water directly from streambeds may reflect process rates under more realistic hydrological conditions, but the anisotropic distribution of sediment sizes in natural streambeds, as well as the spatial variability of groundwater inputs and exchange flow hydraulic gradients, makes it particularly difficult to track changes in water quality along specific subsurface flow paths, and therefore to assign changes in water quality to specific sediment conditions.

We took a hybrid approach, placing flow-through mesocosms filled with two contrasting sediment mixes side-by-side on a natural streambed. This allowed us to monitor water quality changes along defined interstitial flow paths, while maintaining differences in hydrological conditions, such as exchange flow velocity and sediment infiltration rates. Another benefit of using mesocosms was that exchange zone volume was fixed and flow-path water was isolated from the influence of adjacent sediments and upwelling groundwater. These qualities made an in situ mesocosm approach particularly suitable for investigating the influence of sediment size distribution on interstitial nutrient transformations.

\section{Materials and methods}

\section{Site description}

Our experiment was conducted in the South Branch of the North Fork Navarro River, a third-order stream in the coastal mountains of Northern California. Land cover in the South Branch basin consists of mixed redwood (Sequoia sempervirens [D. Don] Endl.) and Douglas fir (Pseudotsuga menziesii [Mirbel] Franco) forest growing on steep, unstable hillslopes underlaid by Franciscan formation sandstone and shale. The entire South Branch basin is privately owned and actively managed for sustainable timber harvest. Base flow was relatively steady during our study ranging from 0.10 down to $0.05 \mathrm{~m}^{3} \mathrm{~s}^{-1}$. Low surface water DIN levels $\left(<10 \mu \mathrm{g} \mathrm{l}^{-1}\right)$ and low molar N:P ratios (TN:SRP $<2$ ) suggest that primary productivity was nitrogen limited (Fig. 1). 


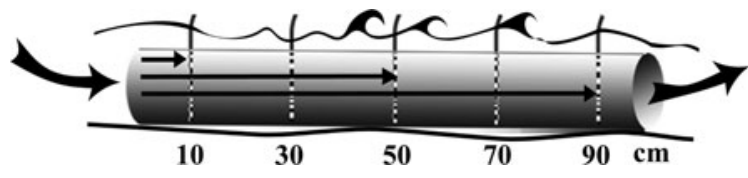

Fig. 1 Gravel-filled pipes $(100 \mathrm{~cm} \times 15 \mathrm{~cm}$ diameter $)$ were used to examine DIN transformations along interstitial flow paths in isolation from the confounding effects of bedform geometry and upwelling groundwater

Hyporheic mesocosms

Mesocosms were constructed from 10 PVC pipes (15 cm diameter $\times 1 \mathrm{~m}$; Fig. 2), 5 filled with gravel and small cobble taken from a dry meander bar (designated coarse sediment treatment) and 5 filled with a mixture of cobble, gravel, pebbles, and sand taken from a different sediment patch on the same meander bar (fine sediment treatment). Details of sediment size distributions are provided graphically in Fig. 2a. Prior to filling, sediments were rinsed with stream water to minimize initial differences in POM content. After filling, water was poured through upright mesocosms while tapping with a hammer to compact sediments and to prevent later settling that would allow unobstructed water flow along inner edges, rather than through the sediments. Galvanized steel hardware cloth $(6 \mathrm{~mm})$ affixed at open ends retained sediments. Inspection upon experiment completion confirmed that sediments remained firmly packed against inner walls. Alternating treatments, mesocosms were submerged side-by-side on the streambed in alignment with surface flow to induce surface water flux through the sediments. Mesocosms were incubated for 60 days prior to sampling to allow biofilm development. Perforated tubes extending from mesocosms at $10 \mathrm{~cm}$ intervals from the upstream end allowed collection of interstitial water samples at different flow path lengths.

Water chemistry and hydrodynamics

Water samples were pumped from 10, 30, 50, 70, and $90 \mathrm{~cm}$ sampling tubes and from surface water immediately upstream from mesocosms with a peristaltic pump and collected into 15-ml polypropylene centrifuge tubes. To minimize disruption of the flow field, water samples were pumped slowly $\left(\sim 5 \mathrm{ml} \mathrm{min}^{-1}\right)$ starting at the most downstream sampling port $(90 \mathrm{~cm})$. The corresponding port for each mesocosm was sampled before proceeding to the next upstream sampling port, allowing a 15 -min recovery period between ports for any given mesocosm. Samples were immediately adjusted in the field to $\mathrm{pH}<2$ with concentrated sulfuric acid to prevent further microbial nutrient transformations and then placed on wet ice for transportation to the lab where they were stored at $4^{\circ} \mathrm{C}$ until analysis. We determined $\mathrm{NH}_{4}{ }^{+}$and $\mathrm{NO}_{3}{ }^{-}+$ $\mathrm{NO}_{2}{ }^{-}$by spectroscopy on a Lachat QuickChem ${ }^{\circledR}$ 8000 Flow Injection Analyzer using the phenolate method and the cadmium reduction, diazotization method, respectively (method detection limit $=$ $2 \mu \mathrm{g} \mathrm{N}^{-\mathrm{NH}_{4}}{ }^{+} 1^{-1}$ and $0.25 \mu \mathrm{g} \mathrm{N}-\mathrm{NO}_{3}{ }^{-}+\mathrm{NO}_{2}{ }^{-} \mathrm{l}^{-1}$; reporting limit $=5 \mu \mathrm{g} \mathrm{N}-\mathrm{NH}_{4}{ }^{+} 1^{-1}$ and $2 \mu \mathrm{g} \mathrm{N}-\mathrm{NO}_{3}{ }^{-}$ $+\mathrm{NO}_{2}{ }^{-} 1^{-1}$ ). Interstitial dissolved oxygen and water temperatures were measured to the nearest $0.1( \pm 0.4)$ $\mathrm{mg}^{-1}$ and $0.1( \pm 0.8)^{\circ} \mathrm{C}$ at $10 \mathrm{~cm}$ intervals along mesocosms with a Fisher Traceable portable dissolved
Fig. 2 a Cumulative weight distribution of coarse (open circles) and fine (closed circles) sediment mixes used to fill mesocosms $(N=3)$. b Individual and mean specific discharge through mesocosms $(N=5)$
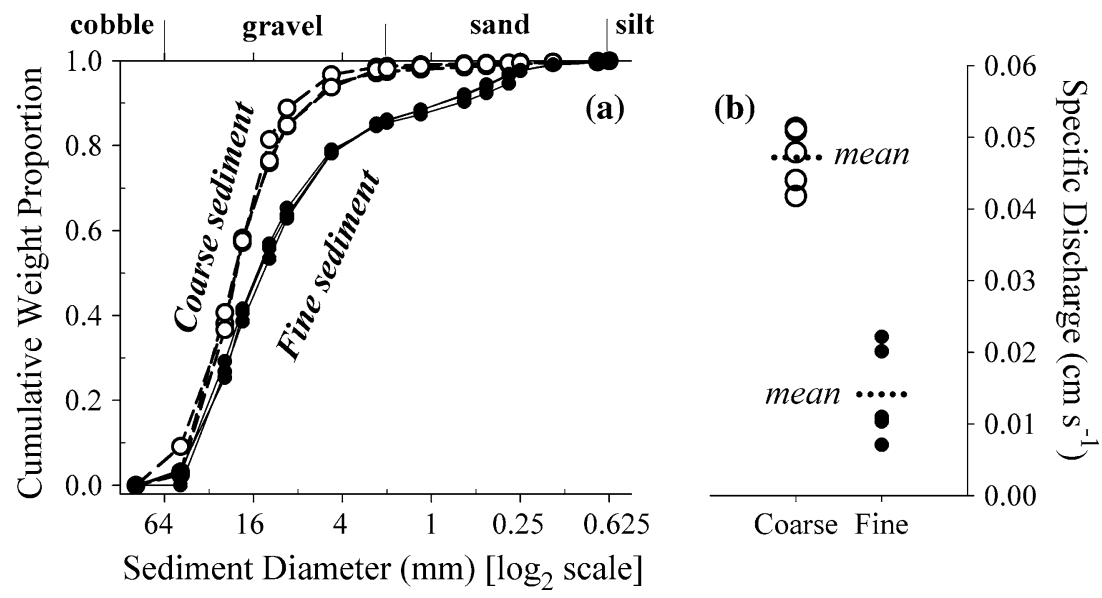

Sediment Diameter (mm) $\left[\log _{2}\right.$ scale]
Coarse Fine 
oxygen meter immersed in a 15-ml beaker while interstitial water was pumped into the beaker at a rate of approximately $15 \mathrm{ml} \mathrm{min}^{-1}$.

Following water sampling, we estimated the average water velocity through mesocosm sediments so that we could calculate water and solute flux. An instantaneous pulse of Rhodamine WT dye was injected through the $30-\mathrm{cm}$ sampling port and its passage monitored at the $50-\mathrm{cm}$ port by pumping time-integrated water samples at $2 \mathrm{ml} \mathrm{min}^{-1}$ over 2-min intervals. Rhodamine WT concentrations in the samples were measured on a Turner Quantech digital filter fluorometer and plotted against time after injection, with the tail of the pulse extrapolated from an exponential function fitted to late time data. The pulse travel time was calculated as the passage time of half the solute mass. Average linear water velocity (v) was calculated from the pulse travel time divided by the travel length between the injection port and the monitoring port $(20 \mathrm{~cm})$. We calculated surface water exchange flux through mesocosms $(q)$ and DIN flux at each sampling port, indicating the solute mass flux normal to the pipe cross section and scaled up to a square meter cross-sectional area,

$q=v \cdot n$,

DIN flux $\left[\mu \mathrm{g} \mathrm{s}^{-1} \mathrm{~m}^{-2}\right]=c q \cdot 10^{3}$,

where $n$ is sediment porosity, $c$ is interstitial DIN concentration $\left(\mu \mathrm{g}^{-1}\right)$, and multiplication by $10^{3}$ converts $1^{-1}$ to $\mathrm{m}^{-3}$. To calculate rates of net DIN uptake or production between each sampling port, we subtracted DIN flux at the upstream port from DIN flux at the downstream port and then divided by the linear distance between sampling ports to normalize between ports separated by different lengths. Sediment respiration rates were measured for the entire length of each mesocosm by regressing dissolved oxygen concentration at each port against the interstitial travel time to that port (flow path length divided by $v$ ). Respiration rates are multiplied by porosity to convert concentration to units of wet sediment and are reported as volumetric rates $\left(\mathrm{mg} \mathrm{O}_{2} \mathrm{~m}^{-3}\right.$ wet sediment $\mathrm{s}^{-1}$ ).

\section{Sediment properties}

At the completion of field procedures, mesocosm sediments collected from the vicinity of each sampling port were initially wet-sieved over a $0.075-\mathrm{mm}$ screen, then dried and dry-sieved through screen sizes $50,25,19,12.5,9.5,4.75,2.36,2,1.18,0.600,0.425$, $0.300,0.250,0.150$, and $0.075 \mathrm{~mm}$ to determine particle size distributions. Sediment properties from only three mesocosms of each treatment were analyzed due to the low variability found between replicates in the initial mesocosms analyzed. Particle size distributions were plotted on a $\phi$-scale $\left(-\log _{2}\right.$ [diameter]) as cumulative weight percent passing through each sieve. To determine the weight percent of coarse particulate organic matter (CPOM), defined as organic particles retained by a $1.18-\mathrm{mm}$ sieve, sediments retained by the $1.18-\mathrm{mm}$ and larger sieves were recombined for each sample following size fraction analysis, and a 10-20-g subsample was dried at $105^{\circ} \mathrm{C}$, weighed, combusted at $450^{\circ} \mathrm{C}$ for $4 \mathrm{~h}$, wetted, redried at $105^{\circ} \mathrm{C}$, and reweighed. The proportion of subsample weight lost on ignition was then multiplied by the weight percent of sediments retained by the $1.18-\mathrm{mm}$ sieve (previously determined in the size fraction analysis). The weight percent of fine particulate organic matter (FPOM) was similarly determined using sediments that passed the 1.18-mm sieve. However, a portion of loose FPOM $(>0.075 \mathrm{~mm})$ was lost during the initial wetsieving process. Effective porosity $(n)$ was determined gravimetrically using two sub-samples from each of the six mesocosms analyzed.

\section{Statistical analyses}

To test for sediment treatment effects on interstitial $\mathrm{NO}_{3}{ }^{-}+\mathrm{NO}_{2}{ }^{-}$, DIN flux, and $\mathrm{O}_{2}$, we used separate repeated measures analysis of variance (rmANOVA) tests with sediment treatment as the between subjects factor and sampling port as the within subjects factor for each test. To determine whether DIN production or uptake was significantly different from zero for each flow path segment, independent, one-sample, 2-tailed $t$ tests were performed using Bonferonnicorrected significance thresholds. Two-way analysis of variance (ANOVA) followed by Tukey's honestly significant difference test (HSD) was used to compare CPOM and to compare FPOM between sediments at different flow path lengths and in different treatments. Oxygen consumption rates were compared between treatments with an Aspin-Welch unequal variance $t$ test. All statistical analyses were performed using NCSS 2001 (NCSS, LLC.). 


\section{Results}

Physical characteristics

Sediment particle size distributions were consistent within each treatment but markedly different between the two treatments with fine sediment mesocosms having a smaller median particle size compared to coarse sediments $(\mathrm{Med}=14.6,21.1 \mathrm{~mm})$, a higher proportion of small-sized particles (Fig. 2a) and a higher inclusive graphic standard deviation of particle sizes $(\operatorname{SD}[\phi$-scale $]=2.01,1.09)$. More than $20 \%$ of the fine sediment mix was finer than $5 \mathrm{~mm}$, while less than $5 \%$ of the coarse sediment mix was finer than $5 \mathrm{~mm}$. In the fine sediment mix, small sediment particles filled the interstitial spaces between the larger particles and reduced porosity $(n=0.297$, $\mathrm{SD}=0.015)$ relative to coarse sediment porosity $(n=0.361, \mathrm{SD}=0.035)$. Average surface water exchange flux (Fig. 2b: specific discharge) through the coarse sediments $\left(M=0.047 \mathrm{~cm} \mathrm{~s}^{-1}, \mathrm{SD}=\right.$ 0.004) was more than three times exchange flux through the fine sediments $\left(M=0.014 \mathrm{~cm} \mathrm{~s}^{-1}\right.$, $\mathrm{SD}=0.007)$. This translated to average exchange flows of $8.3 \mathrm{ml} \mathrm{s}^{-1}(\mathrm{SD}=0.7)$ and $2.5 \mathrm{ml} \mathrm{s}^{-1}$ $(\mathrm{SD}=1.2)$ for coarse and fine sediment mesocosms, respectively.

Particulate organic matter

There was no difference in CPOM between sediment treatments (Fig. 3a; 2-way ANOVA treatment main effect: $\left.P=0.61, F_{1,28}=0.26\right)$ or between sediments at any two flow path lengths regardless of treatment (2-way ANOVA treatment $\times$ flow path length interaction: $P=0.30, F_{4,25}=1.32$ ). However, FPOM in the coarse sediment mesocosms was greater at $10 \mathrm{~cm}$ than at any other flow path length in either sediment treatment (Fig. 3b; 2-way ANOVA treatment $\times$ flow path length interaction: $P=0.014, F_{4,25}=4.05$; Tukey's HSD: $P<0.05$, df $=20$ ).

\section{Solutes}

Concentrations of $\mathrm{NH}_{4}^{+}$were below the method detection limit $\left(2 \mu \mathrm{g}^{-1}\right)$ for all water samples. Therefore, all measurable variation in DIN was caused by changes in $\mathrm{NO}_{3}{ }^{-}+\mathrm{NO}_{2}{ }^{-}$. In both coarse and fine sediment treatments, average interstitial
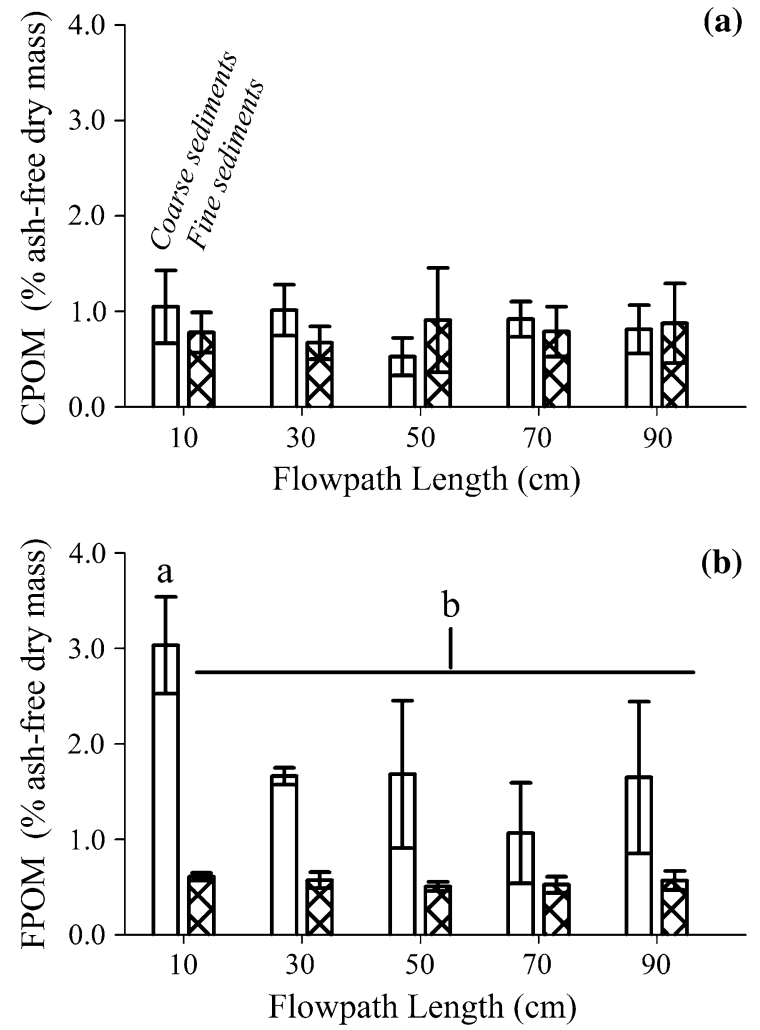

Fig. 3 Weight percent of a CPOM and b FPOM in mesocosm sediments at different flow path lengths. Error bars represent $1 \mathrm{SD} ; N=3$ per treatment. Lower case letters in FPOM graph denote significant difference between FPOM at $10 \mathrm{~cm}$ in coarse sediments and FPOM at all other flow path lengths in both sediment treatments (ANOVA followed by TukeyKramer multiple comparison test)

$\mathrm{NO}_{3}{ }^{-}+\mathrm{NO}_{2}{ }^{-}$was greater than surface water concentrations (Fig. 4a). Concentrations of $\mathrm{NO}_{3}{ }^{-}+$ $\mathrm{NO}_{2}{ }^{-}$were higher in fine sediments than in coarse sediments (rmANOVA treatment main effect: $P=$ $0.000001, \quad F_{1,58}=171.72$; treatment $\times$ flow path length interaction: $\left.P=0.004, F_{5,54}=7.93\right)$ (Eq. 1).

Although DIN (i.e., $\mathrm{NO}_{3}{ }^{-}+\mathrm{NO}_{2}{ }^{-}$) concentrations were highest in the fine sediments, DIN flux was higher in the coarse sediments (rmANOVA treatment main effect: $P=0.009, F_{1,58}=11.57$; Fig. $4 b$ ). The difference in DIN flux between the two treatments was not associated with interstitial processes (rmANOVA treatment $\times$ flow path length interaction: $P=0.14, F_{5,54}=2.09$ ). Rather, a difference in DIN flux was already present at mesocosm inflows prior to contact with mesocosm sediments (note DIN flux at $0 \mathrm{~cm}$ in Fig. 4b). Since DIN flux is the product of specific discharge and DIN concentration (Eq. 2), and 

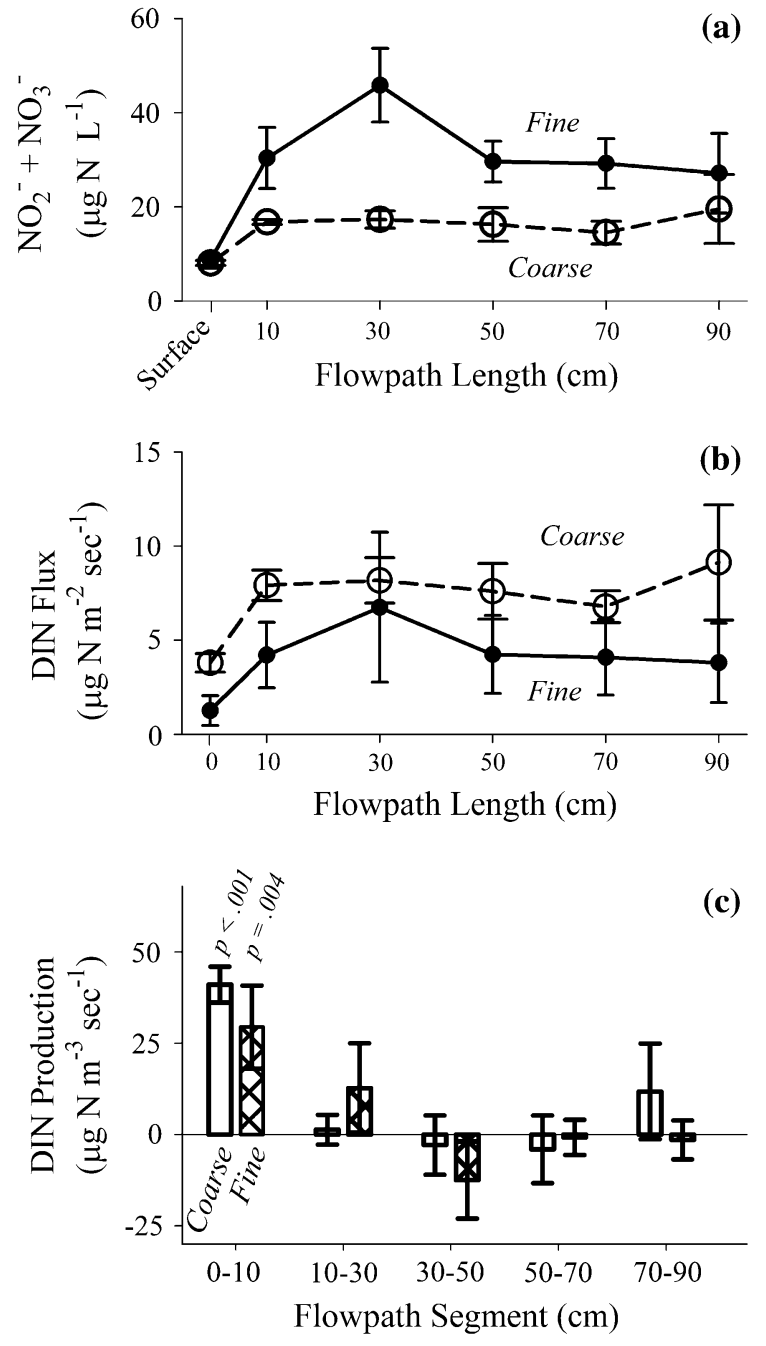

Fig. 4 Average a $\mathrm{NO}_{3}{ }^{-}$concentration and $\mathbf{b}$ dissolved inorganic nitrogen (DIN) flux at each sampling port along mesocosm flow paths, and c DIN net production or uptake between sampling ports. DIN flux is scaled per square meter cross-sectional area, and DIN net production rate per cubic meter of sediment. Probability $(P)$ values indicate net production or uptake rates significantly different from zero (2-tailed $t$ tests). All non-significant production rates had $P>0.05$. There was no significant difference in production between coarse and fine sediments in the $0-10-\mathrm{cm}$ segment (post hoc $t$ test, $P>0.05$ ). Error bars represent $1 \mathrm{SD} ; N=5$ per treatment for all figures

since there was no difference in surface water DIN concentration entering coarse and fine sediment mesocosms (ANOVA, $P=0.53, F_{1,9}=0.44$ ), the difference in DIN flux at mesocosm inflows was caused by higher specific discharge through the coarse sediment mesocosms (Fig. 2b).
Calculations of net DIN production and uptake accounted for differences in DIN flux at the upstream end of each flow path segment, including differences in DIN flux at mesocosm inflows (Fig. 4c). We found significant net DIN production (i.e., production $>0$ ) occurred only within the first $10 \mathrm{~cm}$ of interstitial flow paths in both coarse (one-sample, 2-tailed $t$ test: $P=0.00005, t=18.74, \mathrm{df}=4)$ and fine sediments (one-sample, 2-tailed $t$ test: $P=0.004, t=5.78$, $\mathrm{df}=4)$. No significant net DIN production or uptake occurred beyond $10 \mathrm{~cm}$ (individual $t$ tests: $P>0.05$ for all flow path segments beyond $10 \mathrm{~cm}$ ). A post-hoc comparison did not find a significant difference in net DIN production between coarse and fine sediment treatments in the first $10 \mathrm{~cm}$ of mesocosm flow paths ( $t$ test: $P=0.07$, df $=8$ ).

Interstitial dissolved oxygen was indistinguishable between treatments at each flow path length (rmANOVA treatment main effect: $P=0.06, F_{1,98}=$ 4.68; treatment $\times$ flow path length interaction: $P=0.61, F_{9,90}=0.63$; Fig. 5a). However, oxygen consumption rates scaled to wet sediment volume (Fig. 5b) were higher in coarse sediment mesocosms than fine sediment mesocosms $(M=1.23$, $0.36 \mathrm{mg} \mathrm{m}^{-3} \mathrm{~s}^{-1}, \mathrm{SD}=0.42,0.09 ;$ Aspin-Welch unequal variance $t$ test: $P=0.009, t=4.54$, df $=$ 4.33).

\section{Discussion}

The purpose of this study was to determine whether physical and biological conditions associated with two different sediment size distributions could measurably influence net DIN production or uptake as surface water passed transiently along interstitial flow paths. Both the coarse and fine sediments served as net sources of DIN for surface water. Although DIN rose to higher concentrations in the fine sediment mesocosms (Fig. 4a), there was no difference in net DIN production between the two sediment treatments (Fig. 4c). This discrepancy between DIN concentration and net DIN production occurred because faster exchange flux of surface water through the coarse sediments removed regenerated DIN at a faster rate (Fig. 2b). In reverse, higher interstitial solute concentrations in the fine sediments, relative to coarse sediments, resulted from slower hydrological exchange rates, which allowed solutes to accumulate. 
Fig. 5 a Interstitial dissolved oxygen at different flow path lengths and $\mathbf{b}$ average oxygen consumption rate. Error bars represent $1 \mathrm{SD} ; N=5$ per treatment
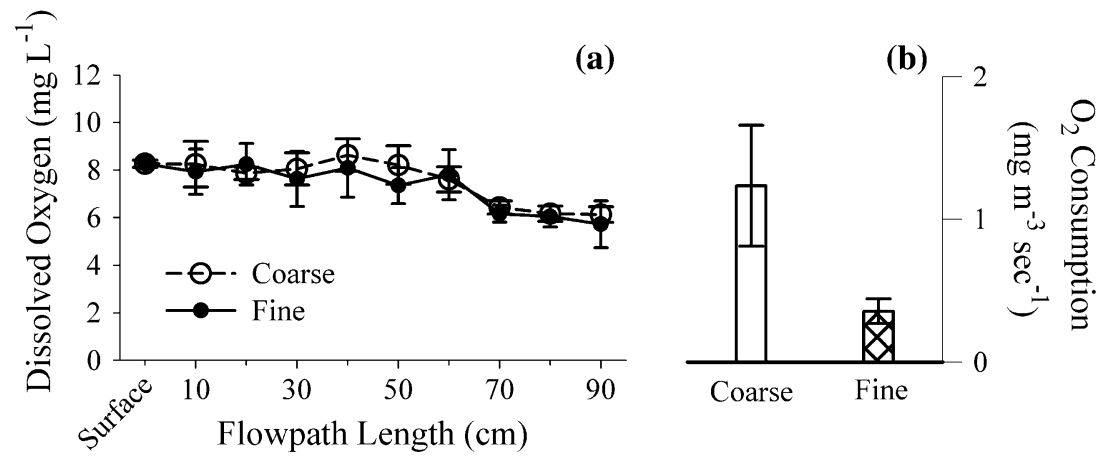

This conclusion agrees with the interpretation of other researchers who observed steeper interstitial solute gradients in finer sediment streambeds of natural streams (e.g., Grimaldi \& Chaplot, 2000; Lefebvre et al., 2005).

The higher per sediment volume respiration rates we measured in our coarse sediment mesocosms (Fig. 5b), and the lack of difference in nitrogen transformation rates between our coarse and fine sediment mesocosms, as indicated by net DIN production rates (Fig. 4c), contrast with the majority of studies that have found respiration rates or other indicators of microbial metabolism are greater in finer sediments (e.g., Jones, 1995; Lefebvre et al., 2005). These other studies usually attribute the higher metabolic activities in finer sediments to greater specific surface area, which provides a substratum for biofilm development (Hargrave, 1972; Bott \& Kaplan, 1985), where substratum refers to the physical structure for biofilm attachment (as opposed to substrate, which refers to consumable organic matter). However, studies have also found strong cross-correlations between microbial activity, smaller sediment sizes, and POM content of sediment mixes (Hargrave, 1972; Bott \& Kaplan, 1985; Claret \& Fontvieille, 1997). The POM fraction of fine sediments is considered a superior substratum for bacterial growth because it also serves as a substrate (Hargrave, 1972). In other words, POM supplies both room and board. Hargrave (1972) found that biofilm $\mathrm{O}_{2}$ consumption rates on POM were two to three orders of magnitude higher than $\mathrm{O}_{2}$ consumption rates on sand grains of similar particle diameter, suggesting small increases in organic matter infiltration and deposition in coarse sediment matrices could yield large increases in microbial process rates. In our study, the significantly higher proportions of FPOM found in the first $10 \mathrm{~cm}$ of coarse sediment mesocosms (Fig. 3b), as well as the apparent though non-significantly elevated FPOM levels along the remainder of mesocosm flow paths, suggest the rapid flow conditions in the center of the channel where mesocosms were situated fostered higher FPOM infiltration rates into coarse sediment mesocosms. Elevated FPOM may explain why coarse sediments exhibited higher respiration rates and similar net DIN production rates compared to fine sediment mesocosms.

Another possible explanation for the discrepancies between our results and studies that have found higher biofilm metabolism in finer sediments is that our in situ measurements preserved the hydrological differences between our sediment treatments, while most of the approaches employed in previous studies have not (e.g., sediment slurry incubations). There is an intrinsic negative relationship between sediment surface area and sediment permeability because grain surfaces exert the drag that inhibits interstitial flow (Bear, 1972). That is why coarse sediments and wellsorted sediments (i.e., sediments with a small standard deviation of sizes) have higher exchange flow rates and faster interstitial velocities than finer or more poorly sorted sediments with more surface area. Both nitrogen processing (Kugaprasatham et al., 1991; Zhu \& Chen, 2001) and respiration (Rasmussen \& Lewandowski, 1998) rates measured in biofilm reactors increase with interstitial water velocity because thinning of the no flow boundary layer at biofilm surfaces enhances solute diffusion, while increased turbulence at higher interstitial flow rates presumably elevates advective mass transport of solutes between bulk flow and biofilm matrices (de Beer et al., 1996). Evidence that these mechanisms also function in porous media is provided by Battin 
(2000), who found higher metabolic activities in streambed sediments sampled from areas with faster interstitial exchange flow, and by a recent study that found a tripling of interstitial flow caused a $48 \%$ increase in oxygen consumption and a $29 \%$ increase in nitrate production rate per sediment volume in flowthrough hyporheic microcosms that had been incubated in a riverbed (Ingendahl et al., 2009).

Since we did not track changes in surface water solutes over the time span that sampled water infiltrated into the mesocosms, we cannot discount the possibility that the longitudinal changes in DIN along mesocosm flow paths merely reflected temporal changes in surface water DIN subject to conservative interstitial transport. However, a rapid change in surface water DIN over this less than $2 \mathrm{~h}$ time span was unlikely. There was no freshet preceding our sampling, and DIN measurements taken in the same month of a previous year showed no diel DIN fluctuations in an adjacent tributary that is less heavily shaded than our study stream (B. Harvey, unpublished data).

\section{Conclusion}

Coarse sediment mesocosms compared to fine sediment mesocosms had similar rates of net DIN production and higher respiration rates per flow path volume. Considering that larger exchange zone volume is typical of coarse sediment streambeds (Valett et al., 1996; Fellows et al., 2001), areal rates of hyporheic nutrient processing in coarse sediment streambeds should exceed rates in streambeds composed of finer material. However, the importance of exchange zone volume to interstitial nitrogen transformations may be limited if transformations are concentrated within the first $10 \mathrm{~cm}$ of subsurface flow paths, as suggested by our study. Nevertheless, the fact that volumetric process rates in our fine sediment mesocosms were not higher than in coarse sediments, despite greater specific surface area, suggests the influence of exchange flow rate, interstitial velocity, and organic matter infiltration may be more critical to interstitial process rates than specific surface area in the range of sediment sizes that we tested.

While mesocosms allowed us to decouple the influence of sediment size from the effects of spatially variable groundwater inputs and anisotropic sediment size distributions, these features of natural streambeds undoubtedly affect the net outcome of hyporheic nutrient transformations. For this reason, there may be some challenge in recoupling our results to field conditions. Despite these limitations, mesocosms are a valuable research tool for controlled experiments and should be employed in future studies modeling complete $\mathrm{N}$ budgets (DIN, DON, and PON) in a broader range of sediment mixes, and under a variety of surface water nutrient conditions, to further understand the relative importance of streambed hydrology and sediment surface area to interstitial nutrient processing.

Acknowledgments This study was partially funded by an NSF graduate research fellowship and UC Davis block grants awarded to Brett Harvey. Thanks to Mendocino Redwood Company for access to field sites, John Harvey for use of UC Davis Pavement Research Lab for sediment analyses, Bruce Hammock, Benjamin Landis, Katie Woodside, Anja Wehrmann, Bill Scott, and Anne Harvey for invaluable field assistance, and Peter Moyle, Tim Ginn, and two anonymous reviewers for helpful comments on the manuscript.

Open Access This article is distributed under the terms of the Creative Commons Attribution Noncommercial License which permits any noncommercial use, distribution, and reproduction in any medium, provided the original author(s) and source are credited.

\section{References}

Alexander, R. B., R. A. Smith \& G. E. Schwarz, 2000. Effect of stream channel size on the delivery of nitrogen to the Gulf of Mexico. Nature 403: 758-761.

Arango, C. P., J. L. Tank, J. L. Schaller, T. V. Royer, M. J. Bernot \& M. B. David, 2007. Benthic organic carbon influences denitrification in streams with high nitrate concentration. Freshwater Biology 52: 1210-1222.

Baker, M. A., C. N. Dahm \& H. M. Valett, 1999. Acetate retention and metabolism in the hyporheic zone of a mountain stream. Limnology and Oceanography 44: 1530-1539.

Battin, T. J., 2000. Hydrodynamics is a major determinant of streambed biofilm activity: from the sediment to the reach scale. Limnology and Oceanography 45: 1308-1319.

Bear, J., 1972. Dynamics of Fluids in Porous Media. Dover Publications, Inc., New York.

Bott, T. L. \& L. A. Kaplan, 1985. Bacterial biomass, metabolic state, and activity in stream sediments - relation to environmental variables and multiple assay comparisons. Applied and Environmental Microbiology 50: 508-522.

Boulton, A. J., S. Findlay, P. Marmonier, E. H. Stanley \& H. M. Valett, 1998. The functional significance of the 
hyporheic zone in streams and rivers. Annual Review of Ecology and Systematics 29: 59-81.

Brunke, M. \& T. Gonser, 1997. The ecological significance of exchange processes between rivers and groundwater. Freshwater Biology 37: 1-33.

Butturini, A., T. J. Battin \& F. Sabater, 2000. Nitrification in stream sediment biofilms: the role of ammonium concentration and DOC quality. Water Research 34: 629-639.

Claret, C. \& D. Fontvieille, 1997. Characteristics of biofilm assemblages in two contrasted hydrodynamic and trophic contexts. Microbial Ecology 34: 49-57.

de Beer, D., P. Stoodley \& Z. Lewandowski, 1996. Liquid flow and mass transport in heterogeneous biofilms. Water Research 30: 2761-2765.

Dodds, W. K., 2007. Trophic state, eutrophication and nutrient criteria in streams. Trends in Ecology \& Evolution 22: 669-676.

Dodds, W. K. \& J. J. Cole, 2007. Expanding the concept of trophic state in aquatic ecosystems: it's not just the autotrophs. Aquatic Sciences 69: 427-439.

Dodds, W. K., C. A. Randel \& C. C. Edler, 1996. Microcosms for aquifer research: application to colonization of various sized particles by ground-water microorganisms. Ground Water 34: 756-759.

Duff, J. H. \& F. J. Triska, 2000. Nitrogen biogeochemistry and surface-subsurface exchange in streams. In Jones Jr., J. B. \& P. J. Mulholland (eds), Streams and Ground Waters. Academic Press, San Diego, CA: 197-220.

Fellows, C. S., H. M. Valett \& C. N. Dahm, 2001. Wholestream metabolism in two montane streams: contribution of the hyporheic zone. Limnology and Oceanography 46: 523-531.

Findlay, S., 1995. Importance of surface-subsurface exchange in stream ecosystems - the hyporheic zone. Limnology and Oceanography 40: 159-164.

Garcia-Ruiz, R., S. N. Pattinson \& B. A. Whitton, 1998. Denitrification in river sediments: relationship between process rate and properties of water and sediment. Freshwater Biology 39: 467-476.

Grimaldi, C. \& V. Chaplot, 2000. Nitrate depletion during within-stream transport: effects of exchange processes between streamwater, the hyporheic and riparian zones. Water, Air, \& Soil Pollution 124: 95-112.

Hargrave, B. T., 1972. Aerobic decomposition of sediment and detritus as a function of particle surface-area and organic content. Limnology and Oceanography 17: 583-596.

Harvey, J. W. \& K. E. Bencala, 1993. The effect of streambed topography on surface-subsurface water exchange in mountain catchments. Water Resources Research 29: 89-98.

Ingendahl, D., E. ter Haseborg, O. van der Most \& D. Werner, 2009. Influence of interstitial flow velocity on hyporheic oxygen consumption and nitrate production. In Borchardt, D. \& M. Pusch (eds), E. Schweizerbart'sche Verlagsbuchhandlung: 119-137.
Jones, J. B., 1995. Factors controlling hyporheic respiration in a desert stream. Freshwater Biology 34: 91-99.

Kasahara, T. \& S. M. Wondzell, 2003. Geomorphic controls on hyporheic exchange flow in mountain streams. Water Resources Research 39: SBH 3-1-3-14.

Kugaprasatham, S., H. Nagaoka \& S. Ohgaki, 1991. Effect of short-term and long-term changes in hydraulic conditions on nitrifying biofilm. Water Science and Technology 23: 1487-1494.

Lefebvre, S., P. Marmonier, G. Pinay, O. Bour, L. Aquilina \& J. Baudry, 2005. Nutrient dynamics in interstitial habitats of low-order rural streams with different bedrock geology. Archiv für Hydrobiologie 164: 169-191.

Malard, F., K. Tockner, M.-J. Dole-Olivier \& J. V. Ward, 2002. A landscape perspective of surface-subsurface hydrological exchanges in river corridors. Freshwater Biology 47: 621-640.

Minshall, G. W., S. A. Thomas, J. D. Newbold, M. T. Monaghan \& C. E. Cushing, 2000. Physical factors influencing fine organic particle transport and deposition in streams. Journal of the North American Benthological Society 19: $1-16$.

Morrice, J. A., H. M. Valett, C. N. Dahm \& M. E. Campana, 1997. Alluvial characteristics, groundwater-surface water exchange and hydrological retention in headwater streams. Hydrological Processes 11: 253-267.

Peterson, B. J., W. M. Wollheim, P. J. Mulholland, J. R. Webster, J. L. Meyer, J. L. Tank, E. Marti, W. B. Bowden, H. M. Valett, A. E. Hershey, W. H. McDowell, W. K. Dodds, S. K. Hamilton, S. Gregory \& D. D. Morrall, 2001. Control of nitrogen export from watersheds by headwater streams. Science 292: 86-90.

Rasmussen, K. \& Z. Lewandowski, 1998. Microelectrode measurements of local mass transport rates in heterogeneous biofilms. Biotechnology and Bioengineering 59: 302-309.

Sheibley, R. W., A. P. Jackman, J. H. Duff \& F. J. Triska, 2003. Numerical modeling of coupled nitrification-denitrification in sediment perfusion cores from the hyporheic zone of the Shingobee River, MN. Advances in Water Resources 26: 977-987.

Stanford, J. A. \& J. V. Ward, 1988. The hyporheic habitat of river ecosystems. Nature 335: 64-66.

Valett, H. M., S. G. Fisher, N. B. Grimm \& P. Camill, 1994. Vertical hydrologic exchange and ecological stability of a desert stream ecosystem. Ecology 75: 548-560.

Valett, H. M., J. A. Morrice, C. N. Dahm \& M. E. Campana, 1996. Parent lithology, surface-groundwater exchange, and nitrate retention in headwater streams. Limnology and Oceanography 41: 333-345.

Zhu, S. M. \& S. L. Chen, 2001. Impacts of Reynolds number on nitrification biofilm kinetics. Aquacultural Engineering 24: 213-229. 